\title{
El templete de Tulán y sus relaciones formativas panandinas (norte de Chile)
}

Le petit temple de Tulán et ses relations panandines au cours du Formatif (nord du Chili)

The temple of Tulan and its panandean relations during the Formative of northern Chile

Lautaro Núñez, Isabel Cartajena, Carlos Carrasco y Patricio de Souza

\section{OpenEdition}

\section{Journals}

Edición electrónica

URL: http://journals.openedition.org/bifea/4858

DOI: $10.4000 /$ bifea.4858

ISSN: 2076-5827

\section{Editor}

Institut Français d'Études Andines

\section{Edición impresa}

Fecha de publicación: 1 diciembre 2005

Paginación: 299-320

ISSN: 0303-7495

\section{Referencia electrónica}

Lautaro Núñez, Isabel Cartajena, Carlos Carrasco y Patricio de Souza, « El templete de Tulán y sus relaciones formativas panandinas (norte de Chile) », Bulletin de l'Institut français d'études andines [En línea], 34 (3) | 2005, Publicado el 08 diciembre 2005, consultado el 04 diciembre 2020. URL : http:// journals.openedition.org/bifea/4858; DOI : https://doi.org/10.4000/bifea.4858

Les contenus du Bulletin de l'Institut français d'études andines sont mis à disposition selon les termes de la licence Creative Commons Attribution - Pas d'Utilisation Commerciale - Pas de Modification 4.0 International. 


\title{
El templete de Tulán y sus relaciones formativas panandinas (norte de Chile) ${ }^{*}$
}

\author{
Lautaro Núñez ${ }^{* *}$ \\ Isabel Cartajena*** \\ Carlos Carrasco**** \\ Patricio de Souza ${ }^{* * * * *}$
}

\begin{abstract}
Resumen
Se ha considerado que las prácticas religiosas templarias es un atributo de las sociedades complejas de los Andes nucleares. Recientes excavaciones en la puna de Atacama, hacia el occidente del centrosur andino, han expuesto un templete bajo un montículo estratificado, datado en los 900-400 años a. C. Sus indicadores ritualísticos -inhumaciones de neonatos humanos, estructuras con petroglifos, ofrendas en fosos, fogones y nichos empotrados en el muro perimetral-, se comparan con las tradiciones religiosas sincrónicas de las tierras altas andinas. En este sentido, las evidencias de Tulán se vinculan con la emergencia de complejidad durante el Arcaico Tardío y su consolidación en la próxima fase Tilocalar del Formativo Temprano (1400-400 a. C.). Comparte con el ceremonialismo Wankarani, del altiplano meridional, la presencia de estructuras y depósitos monticulares constituidos de fogones, desechos de camélidos y patrones de descarte doméstico-ceremoniales.
\end{abstract}

Palabras clave - templete, complejidad religiosa, Formativo Temprano, puna de Atacama

* Proyecto FONDECYT 1020316.

** Instituto de Investigaciones Arqueológicas y Museo, Universidad Católica del Norte, San Pedro de Atacama. Email: lautanunez@netline.cl

*** Departamento de Antropología, Universidad de Chile. Email: icartaje@uchile.cl

**** Programa Magíster en antropología, Universidad Católica del Norte, Universidad de Tarapacá. Email: c_acg@yahoo.com

***** Programa Magíster en antropología, Universidad Católica del Norte, Universidad de Tarapacá. Email: pdesouza@ucn.cl 


\title{
Le petit temple de Tulán et ses relations panandines au cours du Formatif (nord du Chili)
}

\begin{abstract}
Résumé
On a généralement considéré que les pratiques religieuses liées à des temples étaient l'une des caractéristiques des sociétés complexes des Andes centrales. Des fouilles récentes dans la puna d'Atacama, à l'ouest du centre sud andin ont permis de découvrir un petit temple au sein d'un monticule stratifié, daté de 900-400 av. J. C. Les indicateurs qui témoignent de l'existence de rites - inhumations d'enfants, structures avec pétroglyphes, offrandes dans des fosses, fourneaux et niches creusées dans le mur d'enceinte — sont ici comparés aux traditions religieuses synchroniques des hautes terres andines. Dans ce sens, les évidences trouvées à Tulán doivent être rattachées à l'émergence de la complexité lors de la phase Arcaïque récente et sa consolidation pendant la phase Tilocalar du Formatif ancien (1400-400 a. C.). Le site partage avec la culture Wankarani de l'altiplano meridional, la présence de structures et de dépôts en monticules où l'on détecte la présence de fourneaux, restes de camélidés et modèles de rejet domestico-cérémoniel.
\end{abstract}

Mots clés - temple, complexité religieuse, Formatif ancien, puna de Atacama

\section{The temple of Tulan and its panandean relations during the Formative of northern Chile}

\begin{abstract}
It is assumed that religious practices associated with temple structures is an atribute of complex societies in the nuclear Andes. Recent excavations at the western highlands of the Atacama Puna (south central Andes), have revealed a temple structure under a stratified mound dated 900-400 years B.C. We compared its ritual indicators - human newborn burials, structures with petroglyphs, offerings in pits, fireplaces and niches located on the perimetral walls, with synchronous religious traditions in the Andean highlands. We postulated that Tulán evidences are linked with a rising complexity process during the Late Archaic which consolidates during the Tilocalar phase of the Early Formative (1400-400 B.C.). Similar to Wankarani-meridional altiplano, in Tulán we found structures and mound deposits consisting of fireplaces, camelid bones, and patterns of discard derived from domestic refuse and ceremonial activities
\end{abstract}

Key words - Temple structure, religious complexity, Early Formative, Atacama Puna

«Es cada vez más evidente que el origen de la civilización no se inició en un único lugar y por un solo pueblo sino que se trató de un proceso interactivo que requirió la articulación de gentes diversas y separadas entre sí. Es una historia de grandes logros que encierra una importante lección para la humanidad actual».

(Redman, 1991: 10)

\section{INTRODUCCIÓN}

Recientes investigaciones en la vertiente occidental circumpuneña han documentado el desarrollo de ocupaciones pastoralistas más tempranas, con indicadores arquitectónicos y artefactuales complejos anteriores a los 900 a. C. (Benavente, 1981; Núñez, 1992). En general, ha existido cierta tendencia a presuponer que el desarrollo societario periférico al altiplano central y meridional no alcanzó desarrollos autónomos. Sin embargo, el proceso formativo 
circumpuneño está siendo sometido a una revaloración desde una perspectiva regional al interior de particularidades propias del centro-sur andino (Núñez \& Dillehay, 1979; Núñez et al., 2005a).

Las dataciones, en su mayoría provenientes de contextos funerarios, sugerían que las ocupaciones formativas de la cuenca de Atacama no eran más tempranas del límite de los 400 a. C. (Llagostera \& Costa, 1999; Tarragó, 1989). La identificación de la fase Tilocalar con asentamientos aldeanos localizados en el extremo SE de la cuenca de Atacama, con fechas fluctuantes entre 1400-400 a. C., permitió abrir una insospechada profundidad cronológica e identificar una complejidad emergente en plena sincronía con eventos formativos tempranos de los Andes centrales, incluyendo el altiplano meridional (fig. 1). A su vez, se han identificado eventos transicionales entre formaciones sociales arcaicas tardías y agrupaciones aldeanas formativas tempranas, con suficiente autonomía y desarrollo paralelo a los procesos formativos nucleares (Núñez et al., 2005a). En este sentido los cambios estimulantes en las estructuras sociales arcaicas no han sido bien advertidos, y poco se sabe de su transición hacia situaciones formativas complejas: pastoralismo y desarrollo aldeano desde los 1400 a. C. en uno de los hábitats con recursos más discretos del centro-sur andino (puna de Atacama), en donde se han identificado ecorefugios favorables en términos de locus civilizatorios (Núñez et al., 1999a).

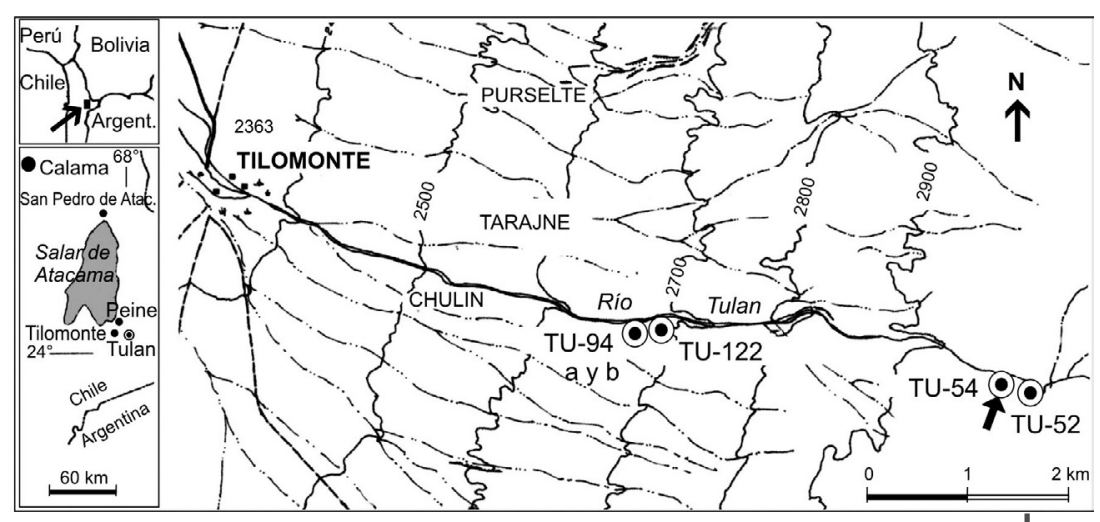

Figura 1 - Ubicación de las aldeas del formativo temprano en quebrada Tulán La flecha indica al asentamiento TU-54 asociado al templete

En efecto, varios logros provenientes de ocupaciones arcaicas de la misma quebrada Tulán se han registrado en el sitio Tulán-54, principal aldea representantiva de la fase Tilocalar: nichos, patrón arquitectónico aglomerado, estructuras subcirculares con grandes lajas empotradas, redundancia de prácticas domésticas (molienda) y uso de fogones, pozos socavados, explotación dominante de camélidos y otros rituales como las incisiones lineales en muros (Núñez et al., 2005a).

Se acepta que la noción de complejidad es un proceso en donde el cambio formativo es la prolongación del arcaico y en este sentido, entendemos por complejidad efectiva el principio que apela a un sistema social que siendo relativamente simple puede lograr una alta probabilidad de evolucionar en un intervalo temporal acotado hacia estructuras de complejidad creciente (Gell-Mann, 1995). En suma, la transición entre los asentamientos arcaicos tardíos (Tulán-52) hacia aldeas complejas con las primeras manifestaciones templarias, como Tulán-54, da cuenta de sostenidos cambios de organización ritual y residencial como reflejo de una reorientación de la economía de subsistencia hacia el pastoralismo y una mayor intensificación de prácticas de intercambio regional complementarias de larga distancia, recurrente en diversas regiones andinas (Aldenderfer, 1990; Aschero, 1994).

Por lo anterior, la construcción de un templete, durante el desarrollo de la fase Tilocalar, se relaciona con la sociedad arcaica local y su eclosión formativa temprana, sustentada mediante 
nuevas prácticas sociales y religiosas capaces de movilizar fuerza de trabajo y creencias compartidas en un ideario plenamente pastoralista. Así, el régimen corporativo se institucionaliza tempranamente a través de una cierta centralización, puesto que la distribución de las aldeas de esta fase no estarían ajenas a un locus ritual común localizado en Tulán-54 (Beck, 2004; Feldman, 1985; Renfrew, 1974). El interés por conocer la naturaleza de los estilos de vida y religiosidad aldeanas en contextos civilizatorios emergentes, al interior de procesos evolutivos sociales, ha transcendido en distintos territorios andinos (Arnes, 1991; Flannery, 1972; Redman, 1978; Rose, 2001). La región circumpuneña de acuerdo a nuestros estudios no está exenta de involucrarse en esta problemática, en especial cuando el modelo de investigación vigente se ha orientado a definir el proceso de complejidad desde su raigambre arcaica hasta los indicios de las innovaciones formativas (Núñez et al., 1999a).

Las sociedades de los Andes Centrales se han definido en torno a una arqueología monumental configurando un «estadio cultista» (Bennett \& Bird, 1960), que pasó a constituir en la costa y valles asociados un proceso original de complejidad arcaica en notables templos públicos de convocatoria calendarica hacia los albores de la civilización (Moseley, 1985). Esto incluye posteriormente su relación con sociedades agrarias (Burger \& Salazar Burger, 1985), además de los templetes de las tierras altas como Chiripa y Tiwanaku, sostenidos por asentamientos dispersos agropastoralistas (Ponce, 1964; 1970), construidos con ingentes inversiones de trabajo mancomunal a lo largo de varias generaciones en un marco de complejidad social, institucional e ideológica, con espacios diferenciados de uso comunal y ritualístico. En este sentido, es importante destacar el aporte de la sociedad cazadora-recolectora-domesticadora de las tierras altas en el surgimiento de ideologías regionales (Burger, 1985; Moseley, 1975; 1985). A una escala menor, pero con similar complejidad, el Templete Tulán es también un segmento crucial de la religiosidad altoandina sustentada en ancestros arcaicos independientes entre sí dando lugar a una ritualidad institucionalizada propiamente circumpuneña.

\section{CARACTERÍSTICAS DE LA FASE TILOCALAR}

La fase Tilocalar se ha definido principalmente en el sitio Tulán-54, compuesto por un asentamiento aldeano y un templete asociado, ubicado al SE de la cuenca de Atacama (norte de Chile), en quebrada Tulán (3000 m.s.n.m.) perteneciente al Formativo Temprano. Durante su desarrollo existía un adecuado soporte alimenticio más ganadero que agrícola (crianza intensiva de camélidos), en un locus óptimo con recursos estables: vegetación arbórea, forraje, materiales de construcción, agua, canteras líticas, vetas cupríferas y otros recursos de corta distancia. De los estudios zooarqueológicos se desprende que, en un contexto de crianza de animales domésticos, es frecuente la caza de camélidos silvestres, lo que indica que las cacerías eran actividades regulares entre las comunidades pastoralistas formativas tempranas, por una parte, orientadas a la preservación de los rebaños de llamas y por otra, a la obtención de pieles, fibras y carne de especies silvestres (Cartajena et al., 2003). Frente a la dieta carnea dominante el registro de plantas alimenticias cultivadas es escaso, salvo la presencia de maíz en la aldea Tulán-85 datado en 700 a. C. y algunos granos a comienzo de ocupación en cueva Tulán-55 datado a los 900 a. C. También es escaso el registro de cucurbitáceas, ají y quinua en el asentamiento Tulán54 (Holden, 1991). La alta presencia de implementos de molienda indicaría la preparación de comidas y de pigmento rojo. Al respecto, llama la atención la ausencia de algarrobo y chañar. No obstante, su molienda podría haberse realizado en el cercano oasis de Tilomonte, donde se situaba el bosque, a través de campamentos especializados, esto es, en la preparación de harinas de mayor utilidad en términos de transporte y conservación (Núñez et al., 2004).

Las aldeas de la fase Tilocalar (Tulán 122, 85 y 54) son contemporáneas entre sí y corresponden a estructuras residenciales subcirculares aisladas o conglomeradas y muros levantados con bloques verticales, empotrados en pisos socavados, incluyendo hiladas superiores con lajas horizontales y pozos socavados junto a nichos, cubiertos por depósitos que conforman túmulos extendidos. Se advierte en estas aldeas un fuerte énfasis en prácticas ceremonialistas en términos de ritualidad 
funeraria infantil, tanto en la disposición de neonatos entre lápidas como «cajitas», en los inicios de los depósitos de desechos (Tulán 85) o en un modo más ritualizado como en el templete de Tulán-54, esto es, en fosos con una o dos inhumaciones asociadas a las cámaras o nichos empotrados en el muro perimetral.

La aldea Tulán-54 presenta entre sus indicadores culturales cerámica monocroma caracterizada por sus colores grises y negros dominantes con tratamiento superficial alisado, pulido y algunas bruñidas con una mayoría de tiestos domésticos de paredes anchas, desgrasantes de granos gruesos y práctica ausencia de asas (Uribe, 2004), incluyendo la presencia menor de tiestos rojos pulidos e intrusivos corrugados, grabados y digitados. En conjunto, esta alfarería sería la matriz ancestral de la tradición negra-gris pulida de San Pedro de Atacama. Varios fragmentos de pipas de cerámica negra pulida con residuos quemados se han registrado en los depósitos del templete Tulán. Estos no solo se asimilan a aquellos del NO Argentino (Tarragó, 1976; 1989), sino que además están presentes en los montículos de Wankarani (Walter \& Trimborn, 1994 [1966]), diferentes a los sopladores de fuego (Brockington et al., 1995). También se encuentran comúnmente cerámicos fragmentos retomados y discoidales para torteras. El carácter expeditivo del uso de fragmentos de cerámica con filos usados por fricción es un indicador del formativo temprano. En este sentido los fragmentos retomados en Tulán-54, aunque ratifican el uso de estos materiales expeditivos, aquí la óptima disponibilidad de materia prima lítica, habla a favor de una orientación especial o exclusiva para la cerámica desechada, en términos de opción cultural, en donde los fragmentos retomados habrían cumplido un rol más ritualístico que doméstico. El uso etnográfico de estas kallanas entre los aymaras se vincula con actos rituales precisamente como el corte de cordones umbilicales (Solc, 1969).

Otros restos materiales presentes en esta fase corresponden a escasos fragmentos de cestería coiled en depósitos y tres ejemplares completos sobre inhumaciones de neonatos del templete, yesqueros (encendedores), cubiletes líticos, espátulas, agujas y punzones de hueso, fragmentos de placas grabadas con motivos geométricos, aplicaciones decorativas de hematita entre otros. También destacan las labores minero-metalúrgicas a través del registro de un maran (machacador) martillos de extracción y molienda, cobre fundido y abundante presencia de mineral de cobre molido. Las ofrendas funerarias que acompañan a diversos neonatos corresponden a iconos en láminas de oro con rostros opuestos, láminas rectangulares con punteados repujados en sus extremos (Tulán 54) y cucharas de cobre de mango corto (Tulán 85). Todo esto ratifica bien esta orientación en términos de la producción de bienes de estatus.

Por otra parte, la presencia significativa de láminas de toba con filos desgastados transversalmente se relacionaría con la preparación de tientos, actividades que en conjunto enfatiza la orientación laboral pastoralista. Por su parte, la presencia de lascas con filos expeditivos y adherencia de fibras sugiere la aplicación de prácticas de esquila. También se observa una sobreproducción de cuentas y microperforadores que ha sido considerada como un atributo de las sociedades arcaicas del área andina en general y del norte de Chile en particular, alcanzando un incremento sustancial durante el formativo temprano y posterior (Núñez et al., 2005a; Rees, 1999; Rees \& De Souza, en prensa). Durante la fase Tilocalar se tendería a estimular y especializar la producción de bienes de prestigio, creándose demandas recíprocas a través de redes de interacción de corta y larga distancia. Es el caso de la deliberada y exitosa sobreproducción de cuentas de collares de mineral de cobre y conchas del Pacífico y del oriente, constituyéndose en la industria lítica de mayor recurrencia. Esto explica, a su vez, la recepción de otros bienes de prestigio desde los valles piemontanos de las yungas aledañas como caracoles y cebil (alucinógeno) para las prácticas fumatorias en pipas y posteriormente en la inhalación con tubos y tabletas (Tarragó, 1989). Esta amplia circulación de cuentas ende y aquende en los Andes guarda relación con la explotación de una alta diversidad de materias primas locales: de hueso y de mineral de cobre: crisocola, malaquita, turquesa, lapislázuli, identificados en Tulán-54, incluyendo conchas del Pacífico (V.gr. Pecten \& Semele) y del oriente transandino como Strophocheilus (Megalobulimus oblongus).

Por todo lo anterior, durante la fase Tilocalar el surgimiento de arquitectura simbólica, además del estilo de grabados rupestres Tulán-Taira y bienes de prestigio, debería asociarse a la construcción 
de una ideología local junto a cambios institucionales en la esfera política y del poder social (Earle, 1997), de tal dimensión que desde estos eventos formativos tempranos el territorio quedará expuesto a un proceso regional de desarrollo cultural con atributos propios (tesis autoctonista), constituyendo posiblemente uno de los orígenes de las tradiciones circumpuneñas. Esta dimensión ceremonialista y doméstica inserta en la fase Tilocalar se plasmaría en un marco de ritualidad, en donde la autoconstrucción identitaria de la élite se reflejaría en la ritualidad funeraria y sus distintos grados de complejidad organizados al interior de una estructura templaria formal. En este sentido, se acepta que en distintas culturas prehistóricas los ajuares y ofrendas de real prestigio se han sustentado en iconos metálicos y conchas exóticas (Chapman, 1991).

Por otra parte, la ritualidad extra muro de quebrada Tulán-54 se centró en espacios más participativos en donde el imaginario del arte rupestre fue más recurrente en farellones y abrigos bajo roca, con la representación de grandes felinos dominantes sobre camélidos que pudieron representar a iconos andinos como el qoa (Kauffmann, 1976). Efectivamente, la asociación entre camélidos, felinos y aves marcó una triade iconográfica trascendente (Berenguer, 1995; Núñez, 1988; Núñez et al., 2003; 2005b). En este marco del ceremonialismo a escala pública propia del arte rupestre, la construcción de un templete sugiere una deliberada acción de apropiación y diferenciación al crear en el núcleo aldeano un centro del ceremonialismo que involucra a especialistas en su manejo religioso. Si bien es cierto que lo construido es una arquitectura pública, su audiencia debió ser selectiva, y aún dificultosa por la presencia de fogones al interior de espacios estrechos frente a nichos y pisos con pozos cubiertos con ofrendas e inhumaciones infantiles, tal como ocurrió con las plataformas estrechas de los templetes Chiripa (Beck, 2004).

Entre los 450-200 a. C. se habría cubierto la aldea y el templete bajo el montículo estableciéndose el abandono del asentamiento Tulán-54 por causas no determinadas y con ello la disolución de la fase Tilocalar. Se ha indicado que las comunidades formativas circuntiticaca, habrían abandonado sus hábitats a raíz de un régimen de sequía detectado por los $450 \mathrm{a}$. C. (Abbott et al., 1997; Bandy, 2001). Sin embargo, los estudios locales no permiten por ahora correlacionar estos eventos entre el altiplano central y la puna salada. Se propone que esta población habría optado culturalmente por la ocupación de los oasis piemontanos, iniciándose un proceso de mayor aldeanización y producción agrícola en los pisos por debajo de los 3000 m.s.n.m., con control de los ambientes ganaderos altoandinos desde cabeceras sociopolíticas de base agraria (Núñez, 1995; M. Grosjean en Núñez et al., 2004; 2005a).

\section{DESCRIPCIÓN DEL TEMPLETE TULÁN}

En el sitio Tulán-54 se observa una ocupación de ca. $2800 \mathrm{~m}^{2}$ asociada a registros superficiales

y una formación monticular con una cúspide de algo más de ca. $2 \mathrm{~m}$. El proceso de excavación permitió exponer bajo la superficie los cabezales del muro perimetral correspondiente al templete, caracterizado por una estructura subcircular de $9 \mathrm{~m}$ de diámetro equivalente a un espacio interior de $85-90 \mathrm{~m}^{2}$. La construcción es homogénea levantándose el muro periférico de una sola vez, sobre el socavado del subsuelo, creándose un piso «hundido». En el interior se observa un primer nivel del paramento con grandes bloques empotrados verticalmente en la base estéril, quedando cámaras liberadas entre jambas y dinteles, conformando 12 nichos a nivel del piso apegado al

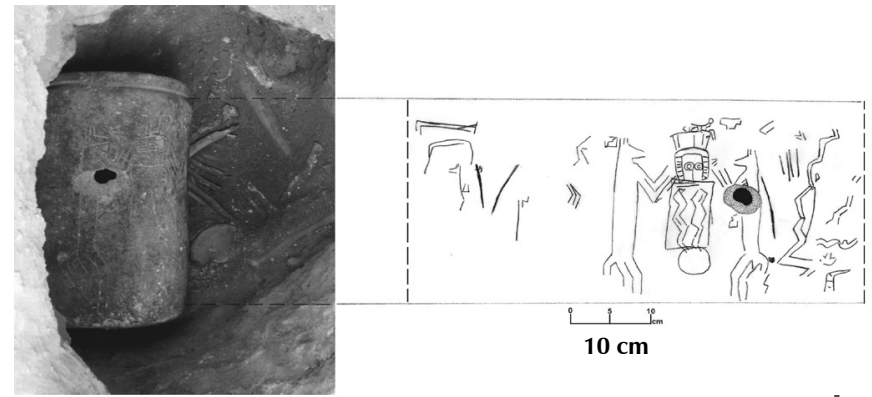

Figura 2 - Cubilete lítico ofrendado junto a la inhumación infantil $n^{\circ} 16$, con dos camélidos humanizados asociados a un personaje central

Tema reiterado y representativo de la ritualidad intra templete 
muro perimetral, asociados a 24 inhumaciones de neonatos (fig. 2). Sobre esta estructura se procedió al levantamiento del segundo nivel, esta vez con la aplicación de bloques semicanteados horizontales con ajustes a base de cuñas líticas. Para el apoyo lateral se acumularon rocas en su exterior y una estrecha rampa inclinada, desde el este, permitía el acceso al centro de la estructura (fig. 3).

En el centro de esta gran estructura se construyó un recinto central ovalado (F), donde se registraron 4 inhumaciones de neonatos bajo lápidas y morteros con ofrendas de significado en términos iconográficos (fig. 4). Entre esta estructura y el muro perimetral se dispusieron muros divisorios estrechos dando lugar a cinco recintos radiales $(A, B, C, D$ y $E)$, los que contienen 10 fogones en cubeta estructurados y en algunos casos sectores de pisos compactos y/o cenicientos provocados por combustión y los pozos laterales con inhumaciones de los neonatos referidos. Se incluyen además ofrendas colocadas en pequeños pozos y petroglifos con diseños de cabezas de camélidos e incisiones longitudinales y jambas pulimentadas. De modo que los bloques verticales con grabados contuvieron también una carga simbólica, junto a los nichos cuya función se relacionaría con la recurrencia de los pozos de inhumación y sus ritos funerarios (fig. 5). Los nichos típicos de la fase Tilocalar ocurrieron previamente en asentamientos arcaicos, como Tulán52, donde su asociación a un pozo indicaría su origen aislado al interior de tempranas unidades domésticas.

Las estructuras interiores y la planta del templete no recibieron
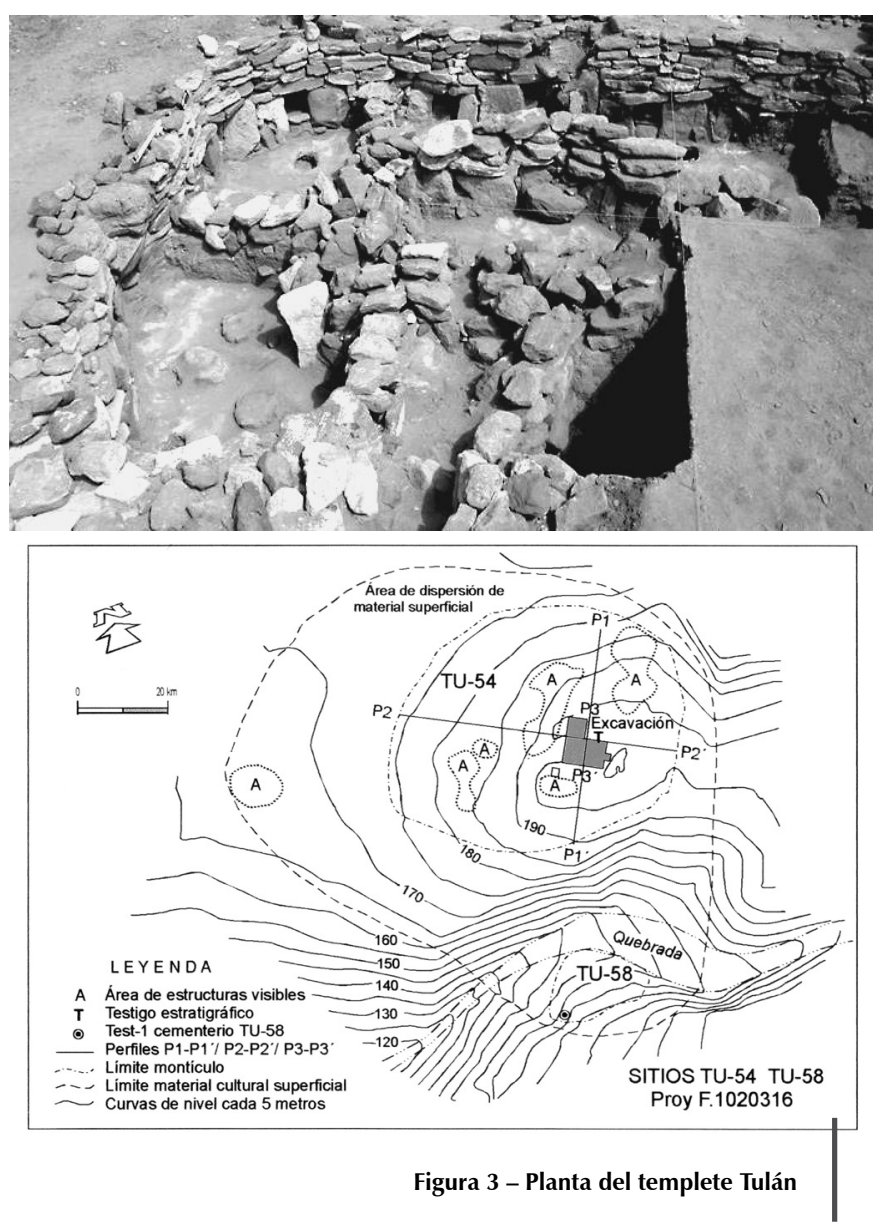
modificaciones posteriores, manteniéndose el eje y los recintos fundacionales hasta sellarse la planta a través de depósitos estratigráficos. A diferencia de las plantas axialmente simétricas de los templetes de los Andes nucleares, aquí se ha asimilado el modelo de la arquitectura arcaica tardía sin trazados rectilíneos, con tendencia a construir con grandes bloques verticales.

El templete acogió los rituales funerarios infantiles con la inhumación de 24 cuerpos dispuestos en pozos, en su mayoría bajo lápidas horizontales, apegados a los nichos del muro perimetral. Se cree que fueron inmolados puesto que los registros dietéticos reconocidos indican una explotación potencial de alimentos, en especial de camélidos, sin evidencias de stress alimenticio. Por otra parte, los análisis de coprolitos señalan patologías infecciosas menores sin efectos letales (Holden, 1991). Se suma la ausencia de recién nacidos fallecidos y la presencia de infantiles escogidos entre 6 a 12 meses (Costa, 2005). 
Los neonatos recuperados se encuentran asociados a ofrendas de prestigio, de origen externo y local, como los ornamentos de conchas exóticas del oriente y los iconos de oro producidos localmente. Las ofrendas de los neonatos incluyen lápidas con incisiones finas o simples, rodados con pigmento rojo, cuentas de conchas del oriente y mineral de cobre, cesto coiled, cubiletes grabados «matados» con escenas de camélidos humanizados en copula y/o enfrentados a

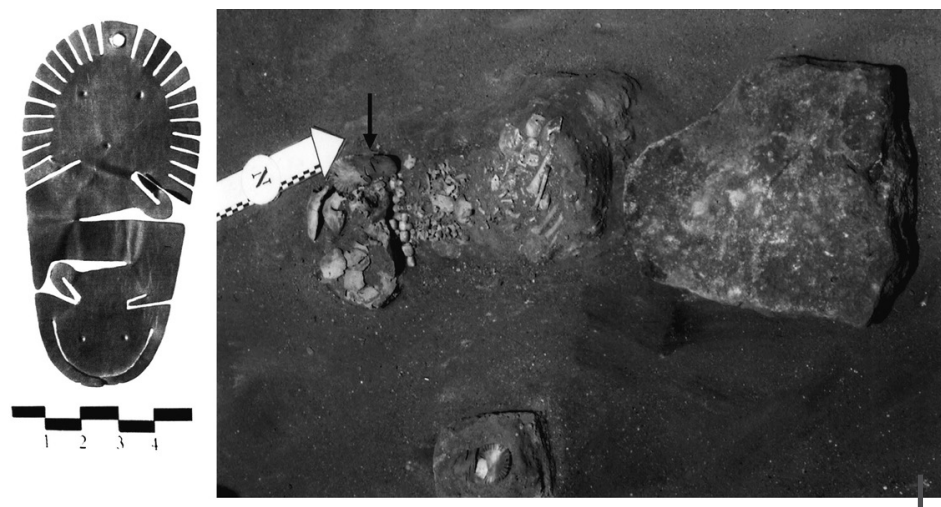

Figura 4 - Principal icono de oro laminado con rostros binarios antropoformo y zoomorfo asociado a la inhumación infantil $n^{\circ} 1$ del centro del templete personaje central y láminas de oro con motivos opuestos (fig. 2).

En general, el registro de neonatos inhumados en pozos desde los pisos de estructuras residenciales formativas es escaso, pero refuerza la tendencia que esos cuerpos no siempre se disponían en los cementerios de jóvenes y adultos en cuanto se les asocia a rituales intramuro, puesto que

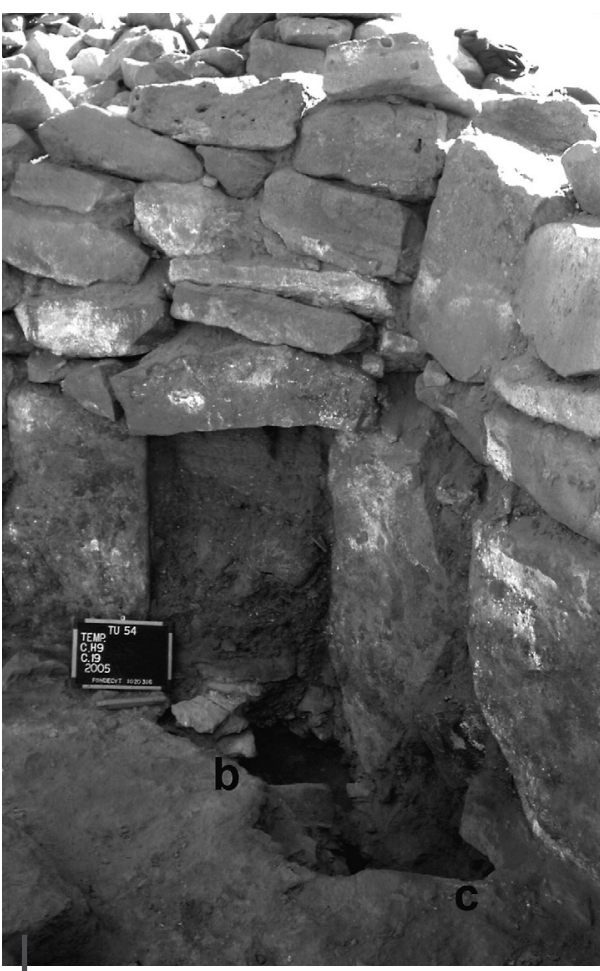

Figura 5 - Muro perimetral del templete con el empotrado de nichos asociados a los pozos de inhumación infantil a nivel del piso originario en el borde sur se registró el cementerio Tulán-58 que contenían 6 cuerpos de adultos fechados en $2340 \pm 50$ A.P. (Núñez, 1999). La recurrencia de las inhumaciones infantiles debió implicar roles trascendentes como nexos entre la práctica social y el imaginario sobrenatural. Los testimonios etnográficos también indican que los infantiles son más vulnerables a la inmolación frente a adversidades catastróficas y sorpresivas (Lindberg et al., 1960) y estarían más expuestos a rituales específicos (Vicent, 1999). El registro de inhumaciones infantiles en aldeas formativas bajo formaciones monticuladas, en las sociedades pastoralistas altiplánicas, ofrecen importantes recurrencias que quizás sean constituyentes de rituales macrorregionales. Al respecto, debe considerarse que en el asentamiento Tulán-85 se registró un sector con siete cuerpos de neonatos dispuestos entre lajas, bajo $150 \mathrm{~cm}$ de depósitos de desechos, fogones y depósitos de ceniza. Esta clase de prácticas funerarias, se ha documentado también en los montículos del complejo Wankarani (altiplano meridional), hallazgos que no excluirían el registro de cementerios propiamente tales fuera de los montículos (Estévez, 1999), tal como ocurre en el asentamiento Tulán-54 (Núñez, 1992).

Otro rasgo particular del templete son los fogones estructurados y abiertos, incluyendo sectores de piso calcinados y cenicientos compactos repartidos en las estructuras interiores. En el fogón 2 de la estructura A se probó que ocurrieron varios eventos deposicionales en relación a distintos momentos de reactivación del fuego, junto a restos óseos que podrían corresponder a comidas 
ceremoniales: camélidos, aves y roedores. Aquí se recuperó abundante mineral de cobre, asociado a cuentas de crisocola y microperforadores. Etnográficamente se ha documentado la íntima relación entre la liturgia de los cantales atacameños y el manejo simultáneo de las ofrendas en el covero (pozo) y la fogata asociada donde queman las yerbas del ritual (coa), tal como ocurre durante la limpia de canales del cercano pueblo de Peine. Esto nos sugiere que los pozos de inhumación del templete se relacionarían con la quema ritual en los fogones adjuntos.

\section{RELACIONES ENTRE EL TEMPLETE Y EL MONTÍCULO DEPOSICIONAL}

El templete está rodeado de estructuras residenciales bajo depósitos de basuras configurando un asentamiento cubierto por estratos continuos de desechos culturales dando lugar a una formación monticular que alcanza una profundidad de 180-200 cm en el sector cuspidal. En el caso del templete de Tulán se advirtió que los residuos domésticos configuraron depósitos estratificados sobre el piso, lo que acentuó el proceso de colmatación que culminó con la cúspide del montículo cubriéndose los cabezales del muro perimetral. Bajo estas condiciones no es fácil segregar en el registro arqueológico cuándo y dónde los residuos responden a actividades ritualísticas de aquellas seculares (Burger \& Burger-Salazar, 1985). Se ha planteado que efectivamente los residuos sobre templetes pueden constituir densos depósitos primarios compuestos de desperdicios desechados de actividades aparentemente domésticas, de naturaleza profana, que encubren o dificultan identificar residuos de ceremonialismo (Burger \& Burger-Salazar, 1985). La recurrencia de similares registros primarios: cerámica local e intrusiva, microperforadores, conchas, minerales de cobre, pigmentos rojos, puntas pedunculadas no agotadas, pipas, conchas de caracoles yungueños, hematita, fragmentos de placas grabadas, entre fogones e implementos de molienda y restos alimenticios, son indicadores de actividades ritualísticas homólogas intra y extratemplete.

El piso original del templete Tulán y sus actos fundacionales se colmataron gradualmente de estos depósitos a través de eventos sacro-seculares intermitentes, no perdiéndose su carácter de estructura ritualizada. Entonces, los elegidos accedían al interior del templete sobre un espacio en que el piso original y compacto transitaba a superficies irregulares y disgregadas, cuyos residuos gradualmente lo cubrían. De modo que el espacio sagrado subyacente se mantenía en las memorias mientras que el túmulo ascendía tanto en el núcleo como en su entorno.

La evidencia artefactual da cuenta de un espacio de «uso mixto», esto es ceremonial y doméstico (Hastorf et al., 2001), con labores de faenamiento y consumo de camélidos, manufacturación de instrumentos y uso de contenedores, constituyendo acumulaciones descartadas en unidades estratificadas primarias derivadas de actividades in situ (Núñez et al., 2005a). En estos contextos «mixtos» es posible identificar evidencias de ritualización, independiente de funciones exclusivamente utilitarias y que otorgan cierto valor especial al registro arqueológico (Binford, 1976; Bermann \& Estévez, 1995). En efecto, cuando los fragmentos de artefactos domésticos presentan un patrón de agrupamiento sobre sectores específicos de un piso residencial y/o ceremonial, o mejor aún si están colocados en nidos de ofrendas o pozos (coveros), es seguro que más que simples escondrijos son ofrendas derivadas de pasajes culticos específicos, tal como ocurrió con dos socavados en el piso del templete Tulán, correspondiente a la disposición de 3 punzones completos de hueso, uno con mango adornado con incrustaciones de hematita brillosa sobre resina y 6 láminas líticas Tulán completas y no usadas.

Situaciones bivalentes en donde la noción de festividad se encubre entre depósitos de desperdicios domésticos son recurrentes en las ocupaciones aldeanas pastoralistas responsables de la construcción de montículos formativos en el altiplano central y meridional y por cierto en el caso de Tulán. El principio para entender la aparente ambigüedad de los significados artefactuales ha sido acogido en un modelo explicativo en donde:

«lo ritual y lo doméstico no son necesariamente mutuamente opuestos» (Hastorf et al., 2001: 36) 
Durante estos eventos formativos el concepto de basura monticulada debe ser revisado desde una óptica no occidental, vinculable más bien con residuos descartados que, sin embargo, en ciertos casos adquieren un rol en el ceremonialismo andino tal como se advierte en el asentamiento Pircas de Tarapacá y Alamito (Núñez, 1984; Núñez Rigueiro, 1998).

¿Qué significa tanto desecho de comida (v.gr. huesos de camélidos) y contenedores para su preparación y brebaje entre fogones al interior del templete? ¿Por qué se cubrió una obra que requirió del traslado y montaje de toneladas de rocas? De acuerdo a los análisis de los depósitos intra y extra templete, no se establecen diferencias sustanciales en cuanto a sus patrones de desechos. Lo que se ha jerarquizado es el lugar sacro central. Esto es, el espacio socializado al interior del templete, cada vez más cubierto, representó funciones similares a lo que ocurre en las cabañas Kollawaya, en donde se identifica un espacio asociado llamado cabildo. Solo allí se concentra el ritual, las quemas de ofrendas, libaciones y manipuleo de la sangre, porque:

«no existen ni deidades sin espacio ni ritual religioso que no se halle ubicado en el espacio» (Rösing, 1994: 197)

Estos hábitos ritualísticos son panandinos en tanto que quienes convocan a los convites (Fernández, 1994) en el área de estudio se reconocen como Puricamayok y cantales, quienes invitan a los convidos. Se encienden fogones, incienso, quema de yerbas aromáticas y ofrendas dispuestas en covero (pozo socavado), tapado finalmente por una laja plana aplicándose simbólicamente un instrumento cortante. La impresión de los últimos pastores perviventes de esta parte de Atacama, sobre los montículos con abundantes restos superficiales de morteros líticos, manos de molienda, industria lítica y sobre todo los notables fogones y huesos de camélidos expuestos; es que allí los antiguos antepasados celebraban sus festejos (Estanilao Ramos, comunicación personal). La idea de comida en abundancia remarcada por la elevación deliberada de las capas de desechos, hace que el concepto étnico de festejo, integre y defina al monumento arqueológico, a través de una connotación de festividad vinculante con comidas generosas ofrendadas a los númenes andinos con implicaciones sacro-seculares.

\section{RELACIONES PANANDINAS}

Las fechas obtenidas en la aldea Tulán-54 incluidas al templete cubren un rango entre 1400 y 400 a. C., dentro del cual las dataciones provenientes del templete ocupan el segmento entre 900 y 400 a. C. Es notable su sincronía con las ocupaciones Chiripa y Wankarani, aunque esta última tendría una ocupación más temprana, es decir, 400-300 años antes de la fase Tilocalar (fig. 6).

Por otra parte, hay contemporaneidad con los centros templarios de los Andes Centrales y Centro-Sur (tierras altas), como aquellos de Chavín (Chakinanani, Ofrendas y Urabarrio), Kotosh (Chavín y Kotosh), Huaricoto (Capillita y Toñi), La Pampa, Huacaloma Layzon (Layzon Huaca loma tardío), Kunturwasi (Kunturwasi e Idalo), Cerro Blanco Pukara, Chiripa Medio y Tardío y las posibles estructuras ceremoniales de Wankarani (fig. 7). De acuerdo con estos antecedentes el ceremonialismo de Tulán es coherente con el énfasis religioso identificado entre las sociedades formativas anteriores a los 400-200 a. C. a lo largo de las tierras altas de los Andes y los primeros indicios de ceremonialismo formativo tardío en valles bajos cercanos al Pacífico (Agüero et al., 2001).

En los ambientes serranos se han identificado templetes semisubterráneos subcirculares durante la fase La Capilla, con espacios restringidos (16 m diámetro) y muros con empotramiento de grandes bloques megalíticos similares a Tulán. La noción del templete hundido que nos interesa se encuentra bien representado en el patrón altiplánico Chiripa con montículos ceremoniales (Ponce, 1970) distribuidos en varios enclaves, definido en tres fases cronológicas: Chiripa Temprano (1500-1000 a. C.) seguido por la fase Chiripa Medio (1000-800 a. C.) contemporáneo con la construcción del templete Tulán y finalmente la fase Chiripa Tardío (800-250 a. C.) sincrónico con su desarrollo y abandono (Beck, 2004; Hastorf et al., 2001; Núñez et al., 2005a). 


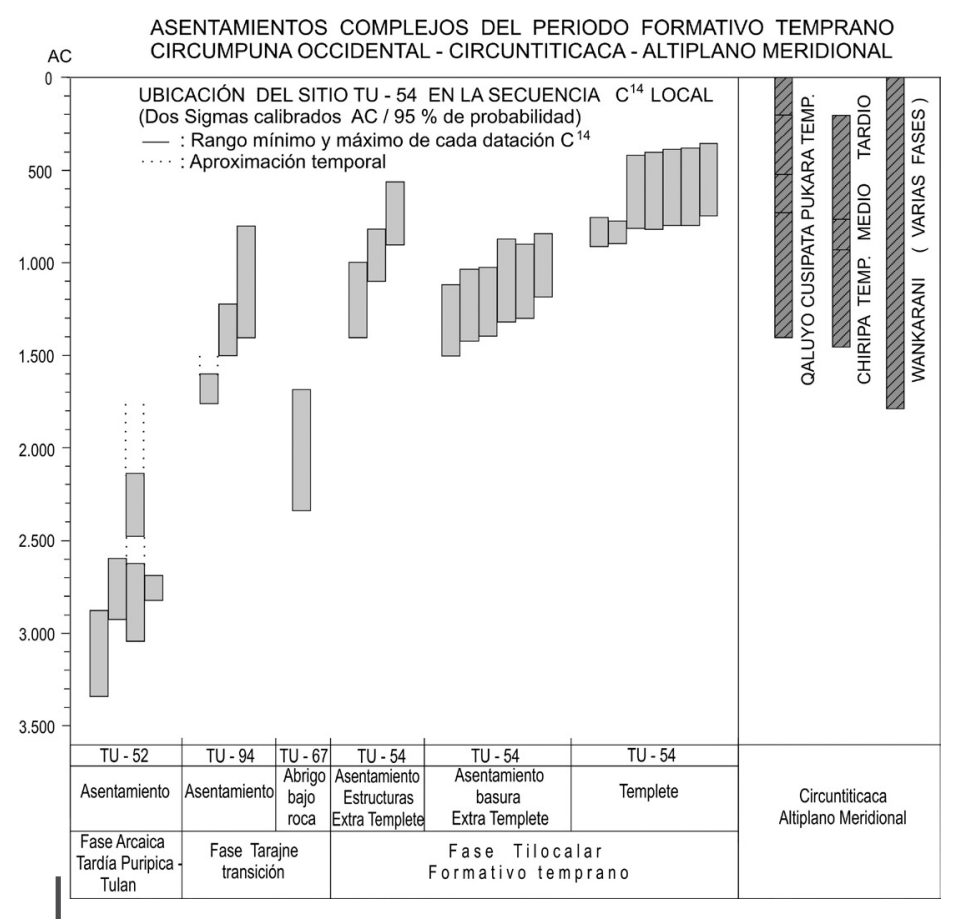

Figura 6 - Secuencia cronológica radiocarbónica de la fase Tilocalar

Se indica el rango del templete y su relación con otros asentamientos formativos tempranos del centro-sur andino
La idea de jerarquizar un patio central hundido rodeado de recintos que se suceden estratigráficamente, es un formato reiterado entre las ocupaciones Chiripa. Estas plataformas rectangulares se cubren y rellenan de basuras una vez abandonadas, reiterándose el ceremonial cuando se cubre un espacio sagrado por otra plataforma. Esta sucesión de plataformas constituyó el alzamiento de los montículos como monumentos visibles y referentes del tiempo social y ritual (Beck, 2004), considerados como los más meridionales del centro sur andino, aunque no debería descartarse que algunos túmulos Wankarani, también sincrónicos con Chiripa y Tilocalar, encubran templetes hasta ahora no identificados, similares en términos de procesos de formación de sitio (Beck, 2004; Bermann \& Estévez, 1993; 1995; Condarco, 2001). Sin embargo, en Tulán no se observa el patrón arquitectónico Chiripa, ni la sucesión de plataformas construidas, aunque se han definido estructuras domésticas superpuestas en torno al templete aún en proceso de excavación. Algunas ideas homólogas independientes se reconocen a través de las relaciones entre templetes e inhumaciones de neonatos. En el sitio clásico de Chiripa también se registran inhumaciones bajo el piso, tapadas con lápidas de las cuales la mitad corresponden a infantes asociados a ofrendas de prestigio en oro, cobre, lapislázuli y conchas, con una ritualidad diferente a la de los adultos (Beck, 2004; Bennet, 1934). Además, la presencia de nichos también se ha constatado en sitios Chiripa Medio (1000-800 a. C.). Estos son generalmente angostos, entre 35 a $66 \mathrm{~cm}$, con sus bases también niveladas con el piso de la estructura, asociado a sectores con arcilla amarilla derivada posiblemente de locis de combustión tal como ocurre en el templete Tulán (Bandy, 2001; Beck, 2004; Chávez, 1988). Las estructuras inferiores de las plataformas Chiripa presentaron fogones de un ritual estandarizado asociado al momento de sellar el piso y abrir el recién nivelado o superior. La superposición de plataformas fue aparejada con quemas (arcilla amarilla), correspondientes al ciclo de rituales, observado en la secuencia de las construcciones (Bandy, 2001). En este mismo orden explicativo se reconoce que entre los pisos de las plataformas Chiripa se

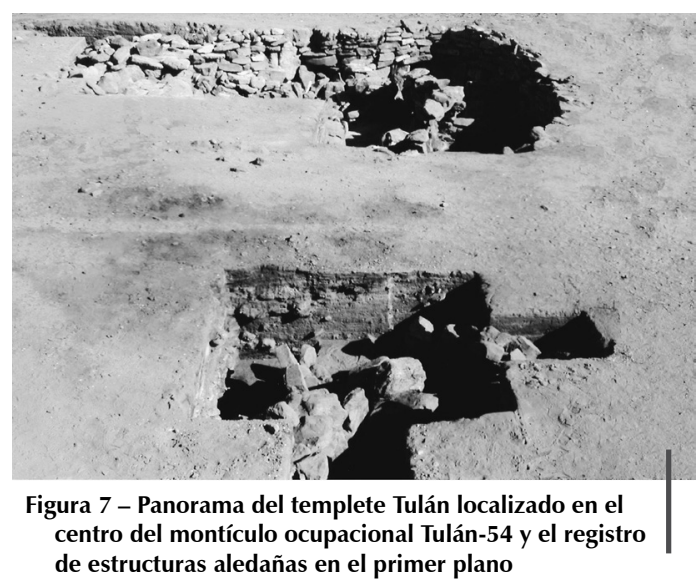


han localizado escasos artefactos diagnósticos, entre ellos restos de molienda con pigmento rojo. No obstante, habría un rango limitado de actividades. Si bien cada plataforma se rellenó con residuos domésticos, este material constituía el marco ceremonial orientado a constituir un montículo como un monumento destacable en el paisaje físico y social que compartían los pastores formativos tempranos con nichos, inhumaciones y fogones asociados, aquí y en distintas regiones de los Andes.

Se han logrado diferenciar distintos locis formativos tempranos con centros ceremoniales en el centro sur andino, con un énfasis que estimuló la circulación caravanera de bienes de status (Bandy, 2001). En Chiripa se han registrado minerales de cobre provenientes de los ambientes desérticos del norte de Chile (Browman, 1981), junto a cuentas de lapislázuli y de conchas, objetos de cobre, oro, plata y obsidiana usada en puntas de proyectiles procedentes de los fuentes del Colca (Arequipa) a más de $300 \mathrm{~km}$ de distancia (Bandy, 2001). Estos ejemplos representan un movimiento de bienes selectivos en términos de prestigio personal y ajuares mortuorios, insertos en redes de caravaneo aún intermitentes o exploratorias (Bandy, 2001; Browman, 1981; Núñez \& Dillehay, 1979). Se ha planteado que gran parte del tráfico de minerales de cobre de color en el área centro-sur andino procede de los distritos mineros del cinturón del cobre de la desértica vertiente occidental de la Puna de Atacama (Núñez, 1987). Por otro lado, la presencia de conchas de mar y caracoles terrestres en contextos Wankarani y en Sierra Mocko, bien podría vincular a los valles de Cochabamba con las cuencas del Loa y Atacama entre las tierras altas y el Pacífico (Estévez \& Bermann, 1996; 1998; Gabelmann, 2001; Walter \& Trimborn, 1994). Más tardíamente, el tráfico de bienes de larga distancia derivado de prácticas arcaicas tardías y formativas tempranas, se mantuvo con las tierras altas (Aschero, 1994; Aguerre et al., 1973; Núñez \& Dillehay, 1979).

El flujo de cerámica de prestigio desde el noroeste argentino hasta la vertiente occidental de la puna de Atacama tales como Vaquerias, Cienaga, San Francisco, se asoció a pipas angulares, plumas de aves tropicales, obsidiana, conchas del oriente y la introducción aquende los Andes de conchas del Pacífico y mineral (óxido de cobre propio de ambientes desérticos). Estos indicadores presentes en las tierras altas aledañas (V.gr. Huayllajara) incluyen cuentas de Choro mytilus y turquesa, asociadas a tiestos negros pulidos clásicos de San Pedro de Atacama, de las fases Sequitor y Quitor (Nielsen, 2001; Tarragó, 1976; Berenguer et al., 1986). Aunque hasta ahora no se han identificado asentamientos aldeanos del patrón Tilocalar en el noroeste argentino, la presencia de cerámica homóloga y otros indicadores en cuevas correspondientes al Formativo Temprano indicarían interacciones significativas (Aschero, 1994; García, 1988-1989; Fernández, 1988-1989).

Estas conexiones incluyeron la ceja de selva (yungas) tanto del noroeste argentino como San Francisco (Dougherty, 1972; Ventura, 1999) y el valle de Cochabamba (Sierra de Mokho) datadas entre 1050 y 200 a. C. Se suma Mayra Pampa entre 1000 y 820 a. C. (con implementos de cobre), el valle alto Chulpapata por los 700-800 a. C., el piedemonte del Chapare, entre 1200 y 100 a. C., incluido un cementerio en el montículo de Conchopata (Mizque) fechado entre 1200 y 600 a. C. asociado a evidencias de intercambio de larga distancia tales como: cobre, plata, cuentas de sodalita, coral, lapislázuli, cerámica intrusiva y conchas del Pacífico (pecten) (Pereira et al., 2001), al igual que cementerios ubicados en el valle Ibirza/Chapare (Pereira et al., 2001).

De acuerdo a las dataciones de la fase Tilocalar las posibilidades de insertarse en este universo centro sur andino de selva a costa es ahora evidente, incluyendo por cierto el altiplano aledaño. En efecto, al sur de La Paz y a través del departamento de Oruro incluida la región intersalar de Uyuni se ubican cientos de montículos correspondientes a las primeras ocupaciones sedentarias agropastoralistas datados entre 1800 a. C. y 270 d. C. Se trata de los túmulos Wankarani de uno a dos hectáreas de ocupación identificados en el altiplano meridional con alta densidad distribucional, incluyendo contactos con el valle de Cochabamba e intenso tráfico caravanero inter-asentamientos debido a las distancias entre sí y con focos distantes de recursos líticos, depósitos de sales y otros (Gabelmann, 2001; McAndrews, 2001).

Se sabía que estas aldeas constituidas de recintos circulares de adobes desmembrados y basuras, databan entre 1200 y 270 a. C. (Ponce, 1970), sin embargo, recientemente se han 
obtenido dataciones más tempranas del orden de los 1400 a. C. (Hastorf et al., 2001). En general, los montículos Wankarani presentan residuos de ocupaciones domésticas con restos líticos, instrumentos óseos (punzones, leznas, espátulas), alta presencia de huesos de camélidos silvestres y domésticos, fragmentación de cerámica monocroma, fundido y escoria de cobre y fragmentos de cerámica retomada. Estos componentes se sitúan entre episodios de acumulación y erosión natural, integrando depósitos culturales de descarte y formación de suelos (Estévez \& Bermann, 1998). Es notable la acumulación de fogones y depósitos densos de ceniza, con restos de paredes de barro asociados a pisos con sedimentos rojizos alterados por combustión (Walter \& Trimborn, 1994; Estévez, 1999). Por otra parte, en el sitio-tipo Wankarani se excavaron ca. de 15 neonatos e infantes decúbito lateral flexionados y ca. 16 adultos. Algunos párvulos presentaron lajas verticales puestas sobre capas de ceniza, otros tapados con lápidas o lajas planas, entre edades precoces con dientes recién expuestos. El hallazgo de uno de estos párvulos recostado y flexionado, similar al patrón Tulán, fue descrito clavado al suelo con una cornamenta afilada de ciervo por la caja toráxica, como neta evidencia de sacrificio (Walter \& Trimborn, 1994). Es importante resaltar que este cuerpo fue hallado junto a otro neonato, vinculados con inmolaciones ejecutadas al interior de una estructura específica, asociado a un fragmento cerámico retomado y afilado. Este registro recuerda a similares restos retomados y usados, incluyendo dos puestos también como ofrendas en dos cuerpos neonatos del templete Tulán. Puesto que se ha postulado la necesidad de complementariedad de recursos de los asentamientos Wankarani (V.gr. maíz), se podría esperar que hayan articulado contactos con comunidades sincrónicas del norte de Chile. Sin embargo, no hay evidencias consistentes de la presencia de sus atributos más representativos, incluyendo la ausencia de su cerámica típica (Estévez, 1999; Ayala \& Uribe, 2003).

Durante el Formativo Temprano coexistían comunidades desde la ceja de selva al Pacífico, independientes del altiplano central, con necesidades de interacciones complementarias (V.gr. bienes de prestigio), que aunque aislados entre grandes espacios despoblados pudieron mantener vínculos que exigen una mayor investigación. Así, de un examen reciente sobre el Formativo Altiplánico, se desprende que ocurrieron contactos caravaneros esporádicos con el flujo de ciertos bienes ceremoniales como sopladores y pipas tubulares (Ayala \& Uribe, 2001).

\section{CONCLUSIONES}

Este primer reconocimiento de una arquitectura ceremonial circumpuneña derivada de estructuras arcaicas locales abre insospechadas expectativas para la comprensión del surgimiento de tempranas prácticas religiosas integradoras, asociadas a comunidades cohesionadas en torno a procesos embrionarios de jerarquización (Renfrew, 1974). Los indicadores arquitectónicos y ritualísticos dan cuenta de una complejidad institucional suficiente como para sustentar un centro de convergencia ritual. Así, la arquitectura pública y la organización política y laboral que la sustenta, con alta inversión de mano de obra, se suma a un conjunto de cambios vinculados con el surgimiento prestigioso del poder social de la élite pastoralista, desde contextos arcaicos tardíos a eventos iniciales y formativos, tal como ocurrió, aunque obviamente en otra escala, en las tierras altas de los Andes centrales (Beck, 2004; Burger, 1985; Moseley, 1985). En general, las obras culticas intervienen en los espacios comunales, dada las necesidades de la élite por consolidar su posición teopolítica apoyada en labores colectivas interfamiliares conducentes a complejidad social e ideológica (Earle, 1997).

El acceso al manejo de prácticas simbólicas entre bienes muebles e inmuebles, permite mediatizar el ordenamiento y control de las actividades convencionales y colectivas, intercediendo las élites entre el imaginario religioso y las necesidades humanas. Fuera de duda, la monumentalidad visible y la mítica del inconsciente colectivo configuraron una trama social que comparte los iconos subordinados con quienes conducen el ceremonialismo en torno al montículo como monumento, tal como se ha observado en el altiplano y ahora en el extremo SE de la cuenca 
de Atacama, como procesos políticos y religiosos independientes al interior de una matriz pastoralista común (Beck, 2004; Núñez, 1992; Núñez et al., 2005a).

Si la estructura subcircular de Tulán formatiza la cosmovisión algo ovalada del universo visible como la visión andina de San Cruz de Pachacuti (Duviols \& Itier, 1992), entonces, el templete representa un caso de arquitectura simbólica en donde la circunferencia se ha interpretado como el mundo y su centro el origen o principio primordial propio de las tradiciones antiguas (Guénon, 1995). En cuanto al centro, se han inhumado cuatros infantes jerarquizados, la ritualidad adquiere una dimensión bipartita de naturaleza centrífuga, mientras que los veinte y cuatro cuerpos infantiles inhumados en el borde perimetral establecen un equilibrio con un ceremonialismo centripeto. En este sentido, núcleo y periferia del piso sacralizado del templete reflejan el axis_mundi de arriba y al propio formato aldeano de abajo, en donde en el templete se han ritualizado los neonatos de los fundadores puesto que en cada una de las divisiones radiales se habrían inmolados los neonatos de los linajes subordinados durante los orígenes de la tradición religiosa Tilocalar.

El manejo de la organización comunitaria pastoralista fue ordenado bajo normas corporativas para los efectos de optimizar un programa arquitectónico más sofisticado. Aunque los sucesos funerarios fundacionales pudieron ser evocados desde una cronología lineal, la imagen del tiempo sacro suele ser evocada desde una percepción subjetiva y mítica a través de festejos periódicos. La estructura del pensamiento religioso andino estaría ordenada por una matriz numinosa, perteneciente al universo de lo sobrenatural que se distingue del espacio doméstico, irradiando una atmósfera de espiritualidad que se conserva y representa en el templete, opuesto a la homogeneidad del ámbito profano (Burger \& Burger-Salazar, 1985; Eliade, 1959, Rösing, 1994).

La asociación entre el inicio y el desarrollo de una ideología regional y la producción de bienes exóticos y de prestigio van aparejados toda vez que la élite local ha logrado identidad y suficiente diferenciación en su forma de acumular riqueza y de intervenir en las necesidades y demandas del «universo» centro-sur andino. Así, la disposición de su potencial artesanal, en términos de productos de status, se orientó hacia la manufacturación de cuentas y ornamentos, inserta en redes de circulación extrarregional propia de las sociedades de rango (Service, 1962; Núñez \& Dillehay, 1979).

La contemporaneidad de tres aldeas pertenecientes a la fase Tilocalar en no más de $20 \mathrm{~km}$ y la presencia de solo un templete en el transecto Tulán no representaría rasgos de ubicuidad, sino más bien se relacionaría con la sacralización de un espacio que centraliza y subordina a la sociedad pastoralista ante iconos y rituales compartidos. Así, el templete ejerció cobertura ideológica, materialización de simbología y legitimización del poder ascendente en la medida que las comunidades se tornaban más complejas. Paralelamente, se requirió de políticas de integración orientadas a controlar el crecimiento de la fuerza laboral pastoralista en vías de asumir logros corporativos orientada a obtener suficiente autarquía socioeconómica. En efecto, una de las características de las sociedades formativas tempranas en las tierras altas, fue la explotación de recursos diversificados en espacios que integran diversos pisos productivos: pecuarios, hortícolas, lacustres y otros, tal como ocurrió en mayor escala con las comunidades Chiripa (Bandy, 2001). Las comunidades Tilocalar llegaron a controlar efectivamente desde los lagos de la alta puna (Meniques-Miscanti) hasta las quebradas intermedias, oasis y vegas del salar, dispuestos en un transecto entre los 4000-2000 m.s.n.m.

En suma, en el piso original del templete se llevaron a cabo prácticas rituales relacionadas con la inmolación e inhumación de neonatos, asociados a fogones, imágenes grabadas y ofrendas en bolsones socavados, dispuestos junto a nichos empotrados en el muro perimetral. El templete como estructura fundacional se nutre de los elegidos para su sacrificio bajo una esfera de integración de linajes, en un espacio donde el axis mundi estaba representado y conmocionado por hechos gravitantes que exigían de un ceremonialismo mayor.

Se ha esclarecido que la sociedad pastoralista de las tierras altas mantuvo un ethos propio de modo que durante el periodo Arcaico Tardío y Formativo Temprano se desarrollaron varias 
«tradiciones religiosas» que, aunque independiente entre sí, compartieron ciertos componentes (Burger, 1985).

Ciertamente, en la sierra de Huanuco (Perú) se han identificado en Kotosh varios edificios superpuestos datados desde 1900 a. C. hasta los primeros siglos de la era, con plantas rectangulares, entre los que destacan el Templo de los Nichitos y el de las Manos Cruzadas, constituyendo montículos elevados separados de los espacios residenciales (Izumi \& Terada, 1972). Precisamente en un contexto arcaico-inicial la «tradición religiosa Kotosh» integra muros perimetrales, empotramiento de nichos en el muro periférico con fogones en cubeta y espacios centrales, incluyendo fosos de uso ceremonial dispuestos en el piso originario (V.gr. La Galgada \& Kotosh). Destacan sus estructuras circulares y rectangulares que incluyen ofrendas de todo el transecto desde las conchas del Pacífico y plumas de aves tropicales, camélidos, venados y cuyes quemados, incluyendo ritos mortuorios junto a las cámaras (Grieder \& Bueno, 1985). Se observa el uso de grandes o bloques verticales bien representados precisamente en el templete circular La Capilla de no más de 16 m de diámetro (Burger \& Burger-Salazar, 1985; Izumi \& Terada, 1972).

En su contexto agropastoralista sedentario los asentamientos Chiripa del altiplano boliviano mantuvieron una secuencia entre 1500 y 100 a. C. asociados a arquitectura pública (templetes), además de monolitos grabados, artesanías de status y surgimiento de autoridad capaz de planificar obras y acciones corporativas (Bennet, 1936; Kolata, 1983; 1993; Bermann \& Estévez, 1995; Hastorf et al., 2001). Hay consenso que los componentes del ceremonial Chiripa constituyen la llamada «Tradición religiosa Yaya-mama» correspondiente al periodo Formativo Medio con irradiaciones hacia el complejo ceremonial Pukara y Tiwanaku (Chávez, 1988; Bandy, 2001). Se trata de centros ceremoniales con convocatorias periódicas entre recintos (plataformas) y patios hundidos, escultura lítica, tiestos cerámicos y trompetas decoradas, ofrendas en espacios sacralizados, formaciones monticuladas, producción metálica de prestigio e inhumaciones de párvulos bajo lápidas, además de comidas consumidas en actos públicos vinculados a prácticas rituales y políticas en el marco de reciprocidad ideológica (Bennet, 1936; Bandy, 2001).

La tradición religiosa Wankarani habría surgido, de acuerdo a Estévez (1999), de un «gran acontecimiento» memorizado entre generaciones, a través de prácticas ceremoniales reiteradas, reflejadas en las quemas de leñas y fogones junto a ofrendas cubiertas por restos de barro, configurando capas compactas derivadas de rituales que evocarían acontecimientos fundacionales como el ceremonial de las inhumaciones de neonatos del templete Tulán y que en el caso de Wankarani se representarían en las litoesculturas de cabezas clavas tanto de camélidos como felínicas. En las capas se han reconocido estructuras residenciales, entre circulares y ovales (Walter \& Trimborn, 1994). Sin embargo, en el montículo San Andrés se han excavado dos estructuras circulares de uso ceremonial de unos $8 \mathrm{~m}$ de diámetro con piso compacto de barroceniza, levantadas con bloques alargados, empotrados verticalmente en la base estéril, cubiertos completamente de depósitos de ceniza bajo la superficie del montículo, esto es, asociados también a quemas rituales (Estévez, 1999). De acuerdo a las excavaciones en estas aldeas bajo montículos se desprende que aquí se desarrolló la tradición religiosa Wankarani compuesta de posibles templetes con pisos compactos, figurinas de arcilla, ofrendas de concentraciones de azadas, manos de molienda con pigmento rojo, litoescultura de cabeza-clavas, cerámica en «nido de ofrenda», hornos estructurados, cucharas, tubos de pipas, sopladores y trompetas, incluyendo implementos metálicos de status: cobre, plata, oro e inhumaciones de neonatos e infantes subyacente al piso y bajo lapidas (Walter \& Trimborn, 1994; Bermann \& Estévez, 1995; Estévez \& Bermann, 1996). Es muy posible que la ritualidad étnica perviviente de carácter pastoralista, provenga, en el altiplano meridional, del complejo Wankarani, tal como lo ratificaría la persistencia del icono litoescultórico focalizado en la cabeza de camélido y con menos frecuencia con rostros de felinos y humanos (Estévez, 1999).

Finalmente, se propone la tradición religiosa Tilocalar como un posible complejo ritualístico representativo de un contexto pastoralista circumpuneño eventualmente distinto al altiplano meridional. Durante el Formativo Temprano, se habría iniciado esta tradición caracterizada por 
la utilización de espacios sacro-seculares de carácter ceremonial y doméstico, con estructura templaria subcircular dedicada a prácticas de inmolación e inhumación de neonatos e infantes asociados a nichos y ajuares de prestigio, además de ofrendas en coveros o «nidos de ofrendas», incluyendo fogones de quemas rituales, grabados de cabezas de camélidos e incisiones en los bloques, incluyendo lápidas o lajas de paramentos con grabados de rostros humanos y temas geométricos. Se suman las actividades redundantes de preparación y consumo de comida, bebidas y producción de manufacturas sobre el piso del templete y su entorno residencial, configurando gradualmente una formación monticulada. Por otra parte, se destaca el culto en torno a grabados de camélidos, felinos, aves, camélidos y felinos en imágenes rupestres del estilo Tulán-Taira y camélidos antropomorfizados copulando (rito de reproducción) y/o acompañando a un personaje central grabado en contenedores líticos. Se acepta que la producción de bienes de prestigio: metálicos, cuentas de status, pigmento rojo, placas grabadas y uso de pipas (alucinógenos) son también componentes del ceremonialismo. Se admite precisamente que la exacerbación religiosa durante el Formativo Temprano habría estimulado la producción de bienes metalúrgicos localizados en los Andes del sur a nivel de invención e irradiación (Lechtman, 1980). Ahora, la identificación de prácticas de extracción, molienda y fundido para piezas de valor simbólico durante la fase Tilocalar, demuestra la viabilidad de las propuestas en torno a un temprano tráfico de piedras preciosas, piezas metálicas, minerales y lingotes, incluyendo especialización laboral (Núñez, 1987; 2005). Así, se habría constituido el inicio del modo caravanero del desarrollo atacameño y el soporte parafernálico del ceremonialismo desde el Formativo Temprano, cuya eclosión se reconoce en la capacidad para instaurar en el medio aldeano la primera arquitectura ceremonial circumpuneña (fig. 8).

UBICACIÓN DEL TEMPLETE TULAN (FASE TILOCALAR) EN LA CRONOLOGÍA DE LOS CENTROS CEREMONIALES TEMPRANOS DE LAS TIERRAS ALTAS, ANDES CENTRALES / CENTRO - SUR ANDINO.

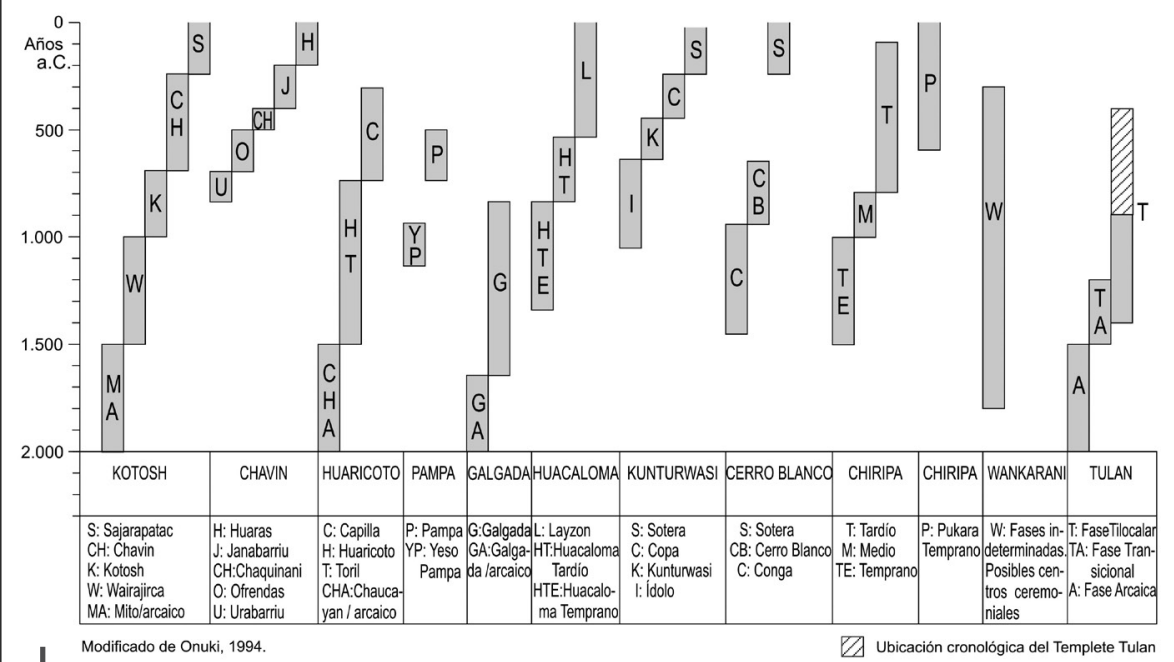

Figura 8 - Dataciones C14 de la fase Tilocalar y de los sectores de la aldea Tulán-54 asociada al templete Tulán y su relación con otros centros ceremoniales de las tierras alto-andinas 
Por último es necesario señalar la excepcional yuxtaposición puneña entre yacimientos arqueológicos y pervivencia étnica. A pesar de las dificultades que reviste el uso de analogías etnográficas, consideramos que éstas pueden ser consideradas como estímulos para interpretar la religiosidad formativa. En este marco, cobran relevancia algunos rituales andinos como el Ch'iayara misa (mesa), que incluye la presencia de un elenco de desechos considerados «inmundicias» semejantes a «basuras» incorporados al ceremonialismo (Rösing, 1991: 115). Por otra parte, la metáfora de asumir que el espacio intra templete se comportó como una gran mesa aymara, tiene sentido si desde la etnografía se admite que la mesa como ofrenda culinaria, permite por reciprocidad, satisfacer el apetito de los seres tutelares, como achachila que es amo y antepasado de la comunidad, además dueño del ganado silvestre y doméstico, incluyendo la lluvia y los infantes (Fernández, 1994). Los dioses andinos solo se satisfacen a través de la «deuda de ofrenda» para permanecer en estado de equilibrio y reciprocidad en términos de recibir ofrendas, sacrificios y rogativas como númenes dueños de las lluvias, alimentos, fertilidad, salud y muertes prematuras. Los achachilas, espíritus de los antepasados, viven en cerros, vertientes, lagunas y otros lugares sagrados y hacia allí son invocados a un espacio de interlocutorio (mesa, nido de ofrenda), donde un selecto colectivo participa en la disposición de las ofrendas, de las libaciones, la quema de inciensos y por cierto las comidas rituales con sacrificios de camélidos (Bouysse-Cassagne, 1987; Rösing, 1994). Los desechos prehistóricos primarios derivados de estas actividades in situ, de carácter sacro-secular, fueron deliberadamente acumuladas para constituir un montículo o relieve artificial que marca en el paisaje social y físico la existencia subyacente de un monumento funerario fundacional y protector, conservado en las memorias y convidos intergeneracionales.

\section{Referencias citadas}

ABBOTT, M. B., BINFORD, M. W., BRENNER, M. \& KOLTS, K. R., 1997 - A 3500 14C High resolution record of water-level changes in lake Titicaca, Bolivia/ Perú. Quaternary Research, 47: 109-180.

AGÜERO, C., URIBE, M., AYALA, P., CASES, B. \& CARRASCO, C., 2001 - Ceremonialismo del periodo formativo en Quillagua, Norte Grande de Chile. Boletín de la Sociedad Chilena de Arqueología, 32: 24-34.

AGUERRE, A., FERNÁNDEZ DISTEL, A. \& ASCHERO, C., 1973 - Hallazgo de un sitio acerámico en la quebrada de Inca Cueva (Provincia de Jujuy). Relaciones de la Sociedad Argentina de Antropología, 7: 197-214.

ALDENDERFER, M. S., 1990 - Late preceramic ceremonial architecture at Asana. Antiquity, 64 (244): 479-497.

ALDUNATE, C. \& CASTRO, V., 1981 - Las chullpas de Toconce y su relación con el poblamiento altiplánico en el Loa Superior. Periodo Tardío, 206 p.; Editorial Kultrun.

ARNES, K. M., 1991 - Sedentism, a temporal shift or a transitional change in hunter-gatherer mobility strategies. In: Between bands and states (Susan Greg, ed.): 103-133; Carbondale: Ed. S.A. Gregg Southern Illimois University Press. Center for Archaeological Investigations Occasional Paper $\mathrm{n}^{\circ} 9$.

ASCHERO, C., 1994 - Reflexiones desde el arcaico tardío (6000-3000 a. P.). Rumitacama, 1: 13-18.

AYALA, P. \& URIBE, M., 2001 - Las sociedades formativas del altiplano circuntiticaca y meridional y su relación con el norte grande de Chile. Estudios Atacameños, 21: 7-39.

AYALA, P. \& URIBE, M., 2003 - La cerámica Wankarani y una primera aproximación a su relación con el periodo Formativo del Norte Grande de Chile. Textos antropológicos, vol. 14, $\mathbf{n}^{\circ}$ 2: 7-30; La Paz. 
BANDY, M. S., 2001 - Population and history in the ancient Titicaca Basin; Berkeley: Universidad de California, Tesis Doctoral.

BECK JR., R. A., 2004 - Architecture and polity in the formative lake Titicaca basin, Bolivia. Latin American Antiquity, 15 (3): 323-343.

BENAVENTE, A., 1981 - Chiu-Chiu 200: Un campamento de pastores. Universidad de Chile, Tesis de Grado.

BENNETT, W. C., 1934 - Excavations in Bolivia. Anthropological Papers of the American Museum of Natural History, XXXV (IV); Nueva York.

BENNETT, W. C., 1936 - Excavations in Tiahuanaco. Anthropological Papers of the Museum of Natural History, XXXIV (III); Nueva York.

BENNET, W. \& BIRD, J., 1960 - Andean culture history, 331 p.; New York: American Museum of Natural History.

BERENGUER, J., 1995 - El arte rupestre de Taira dentro de los problemas de la arqueología atacameña. Chungará, 27 (1): 7-43.

BERENGUER, J., DEZA, A., ROMÁN, A. \& LLAGOSTERA, A., 1986 - La secuencia de Myriam Tarragó para San Pedro de Atacama: un test por termoluminiscencia. Revista Chilena de Antropología, 5: 17-54.

BERMANN, M. \& ESTÉVEZ, J. C., 1993 - Jachakala: A New Archaeological Complex of the Department of Oruro, Bolivia. Annals of Carnegie Museum, 62 (4): 311-340.

BERMANN, M. \& ESTÉVEZ, J. C., 1995 - Domestic Artifact Assemblages and Ritual Activities in the Bolivian Formative. Journal of Field Archaeology, 22 (4): 389-398.

BINFORD, L. R., 1976 - Forty-seven Trip: A case Study in the Character of Some Formation Processes of the Archaeological Record. In: Contributions to anthropology: the interior peoples of Northern Alaska (Hall Jr., ed.): 299-351; Ottawa: National Museums of Canada. Archaeological Survey of Canada Paper, 49.

BOUYSSE-CASSAGNE, T., 1987 - La identidad aymaras. Aproximación histórica (siglos XV y XVI), 443 p.; La Paz: IFEA-Hisbol.

BROCKINGTON, D., PEREIRA, D., SANZETENEA, R. \& MUÑOZ, M. A., 1995 - Estudios arqueológicos del Periodo Formativo en el sureste de Cochabamba 1988-1989, 180 p.; Cochabamba: Universidad Mayor de San Simón. Cuadernos de investigación, Serie Arqueología, 8.

BROWMAN, D. L., 1981 - New Light on Andean Tiwanaku. American Scientist, 69 (4): 408419.

BURGER, R.L. 1985 - Concluding remarke early Peruvian civilization and its relation to the Chavin Horizon. In: Early ceremonial architecture in the Andes (C. B. Donnan, ed.): 269289; Washington D. C.: Dumbarton Oaks Research Library and Collection.

BURGER, R. L. \& SALAZAR-BURGER, L., 1985 - The early ceremonial center of Huaricoto. In: Early ceremonial architecture in the Andes (C. B. Donnan, ed.): 111-138; Washington D. C.: Dumbarton Oaks Research Library and Collection.

CARTAJENA, I., NÚÑEZ, L. \& GROSJEAN, M., 2003 - Los camélidos en la vertiente occidental de la Puna de Atacama: Una visión desde el arcaico temprano al formativo temprano. Ponencia presentada al III Taller Internacional de Zooarqueología de Camélidos Sudamericanos. Instituto Interdisciplinario de Tilcara.

CONDARCO, C., 2001 - Verticalidad e intercambio en dos asentamientos de la cuenca de Paria. Informe final Programa de Investigaciones Estratégicas en Bolivia (PIEB). Convocatoria Regional Oruro, 1999.

COSTA, M. A., 2005 - Informe de determinación de edad de individuos infantiles del sitio Tulán54. Informe de avance Proyecto FONDECYT 1020316. Ms.

CHAPMAN, R. W., 1991 - La formación de sociedades complejas. El sureste de la península ibérica en el marco del mediterráneo occidental, 411 p.; Barcelona: Editorial Critica. 
CHÁVEZ MOHR, K., 1988 - The significance of Chiripa in lake Titicaca basin developments. Expedition, 30 (3): 17-26.

DOUGHERTY, B., 1972 - Las pipas de fumar arqueológicas de la provincia de Jujuy. Relaciones, 11: 83-90.

DUVIOLS, P. \& ITIER, C., 1992 - Juan de Santa Cruz Pachacuti yanqui Salcamaygua. Relación de antigüedades de este Reyno del Piru, 276 p.; Cuzco: Instituto Francés de Estudios Andinos - Centro de Estudios Regionales Andinos «Bartolomé de las Casas». Estudio Etnohistórico y Lingüístico.

EARLE, T., 1997 - How chiefs come to power: The political economy in prehistory, 265 p.; Stanford: Stanford University Press.

ELIADE, M., 1959 - The sacred and the profano, 213 p.; New York: Harcourt Brace and World Inc. (W. R. Trask, trad.).

ESTÉVEZ, J. C., 1999 - San Andrés: un montículo ceremonial de la cultural Wankarani (Informe preliminar); La Paz. Ms.

ESTÉVEZ, J. C. \& BORMANN, M., 1996 - Reporte preliminar de la temporada 1996. Proyecto Arqueológico Oruro. Ms.

ESTÉVEZ, J. C. \& BORMANN, M., 1998 - Reporte preliminar de la temporada 1997. Proyecto Arqueológico Oruro. Ms.

FELDMAN, R. A., 1985 - Preceramic corporate architecture: Evidence for the development non-egalitarian social systems in Peru. In: Early ceremonial architecture in the Andes (C. B. Donnan, ed.): 60-70; Washington D. C.: Donnan. Dumbarton Oaks Research Library and Collection.

FERNÁNDEZ, J., 1988-1989 - Ocupaciones alfareras (2860+160 años a.P.) en la cueva de Cristóbal, Puna de Jujuy, Argentina. Relaciones de la Sociedad Argentina de Antropología, XVII (2): 139-172; Buenos aires.

FERNÁNDEZ, G., 1994 - El banquete aymará: Aspectos simbólicos de las mesas rituales aymaras. Revista Andina, 12 (1): 155-190.

FLANNERY, K. V., 1972 - The origins of the village as a settlement type in mesoamerica and in the near east: A comparative study. In: Man, Settlement and Urbanism (P. J. Ucko, R. Tringham \& E. W. Dimbleby, eds.): 22-53; Londres: Duck Worth.

GABELMANN, O., 2001 - Choroqollo. Producción de cerámica e intercambio de bienes durante el periodo formativo. Un ejemplo del valle Santiváñez, Cochabamba. Textos Antropológicos, 13 (1-2): 197-229 (Rivera, C., Michel, M. R. \& Cipreles, J. M., eds.).

GARCíA, L. C., 1988-1989 - Las ocupaciones tempranas en cueva y aleros en la Puna de Jujuy, Argentina-Inca Cueva, Alero 1. Paleoetnológica, 5: 10-21.

GELL-MANN, M., 1995 - El quark y el jaguar. Aventuras en lo simple y lo complejo, 413 p.; Tusquets editores.

GUÉNON, R., 1995 - Símbolos fundamentales de la ciencia sagrada. Paidos Orientalia, 399 p.; Trad. Tejada, J. L. \& Leva, J.

GRIEDER, T. \& BUENO, A., 1985 - Ceremonial architecture at La Galgada. In: Early ceremonial architecture in the Andes (Donnan, C. B., ed.): 93-110; Washington D. C.: Donnan. Dumbarton Oaks Research Library and Collection.

HASTORF, C. A., BANDY, M., WHITEHEAD, W. T. \& STEADMAN, L., 2001 - El periodo formativo en Bolivia: Regiones y sociedades. Textos Antropológicos, 13 (1-2): 17-91 (Rivera, C., Michel, M. R. \& Cipreles, J. M., eds.).

HOLDEN, T. G., 1991 - Evidence of prehistoric diet from northern Chile: Coprolitos, gut contents and flotation samples from the Tulan quebrada. World Archaeology, 22 (3): 320-331; Londres.

IZUMI, S. \& TERADA, K., 1972 - Andes: Excavations at Kotosh, Peru 1963 and 1966, 354 p.; Tokyo; University of Tokyo Press. 
KAUFFMANN, F., 1976 - El Perú arqueológico, 288 p.; Lima: Kompaktos Ediciones G. S.

KOLATA, A. L., 1983 - The South Andes. In: Ancient South Americans (Jennings, J. D., ed.): 241285; W. H. Freman and Company.

KOLATA, A. L., 1993 - The Tiwanaku, Portrait of an Andean Civilization, 288 p.; Cambridge, Massachussets: The peoples of America, Blackwell Publishers.

LECHTMAN, H., 1980 - The Central Andes: Metallurgy without iron. In: The Coming of the Age of the Iron (Wertime, T. A. \& Muhly, J. D., eds.): 267-334; New Haven: Yale University Press.

LINDBERG, I., PINEDA, E., \& NÚÑEZ, L., 1960 - Algunos aspectos de la vida material y espiritual de los araucanos del lago. Budi Finis Terrae, 28: 58-89.

LLAGOSTERA, A. \& COSTA, M. A., 1999 - Patrones de asentamiento en la época agroalfarera de San Pedro de Atacama (norte de Chile). Estudios Atacameños, 17: 175-286.

MCANDREWS, T. L., 2001 - Organización y crecimiento de los sistemas de asentamientos tempranos basados en aldeas en el altiplano andino sur central. Textos Antropológicos, 13 (1-2):135-145 (Rivera, C., Michel, M. R. \& Cipreles, J. M., eds.).

MOHR-CHÁVEZ, K., 1988 - The significance of Chiripa in Lake Titicaca development. Expedition, 30 (3): 17-26.

MOSELEY, M. E., 1975 - The maritime Foundation of Andean Civilization, 131 p.; California: Cumming Publishing Company Menlo Park.

MOSELEY, M. E., 1985 - The exploration and explanation of early monumental architecture in the Andes. In: Early ceremonial architecture in the Andes (C. B. Donnan, ed.): 29-57; Washington D. C.: Donnan. Dumbarton Oaks Research Library and Collection.

NIELSEN, A. E., 2001 - Ocupaciones formativas en el altiplano de Lípez-Potosí, Bolivia. Textos Antropológicos, 13 (1-2): 265-285 (Rivera, C., Michel, M. R. \& Cipreles, J. M., eds.).

NÚÑEZ, L., 1984 - El asentamiento las Pircas: evidencias de tempranas ocupaciones agrarias en el Norte de Chile. Estudios Atacameños, 7: 152-177.

NÚÑEZ, L., 1987 - Tráfico de metales en el área centro-sur andina: Factos y expectativas. Cuadernos del Instituto Nacional de Antropología, 12: 73-105.

NúÑEZ, L., 1988 - Análisis de domesticación y crianza de camélidos en el Norte de Chile (1986-1987). Proyecto FONDECYT 1017-86. Informe final. Ms.

NúÑEZ, L., 1991 - Tráfico factos y conchas. Boletín de la Sociedad Chilena de Arqueología, 13: 18-19.

NÚÑEZ, L., 1992 - Emergencia de complejidad y arquitectura jerarquizada en la Puna de Atacama: Evidencias del sitio Tulán 54. In: Taller de selva a costa (Albeck, M. E., ed.): 85115; Buenos Aires: Instituto Interdisciplinario de Tilcara, Universidad de Buenos Aires.

NúÑEZ, L., 1995 - Evolución de la ocupación y organización del espacio atacameño. In: Agua, ocupación del espacio y economía comparativa en la región atacameña, aspectos dinámicos (Pourrut, A. \& Núñez, L., eds.): 18-60; Universidad Católica del Norte.

NÚÑEZ, L., 1999 - Fase Tilocalar: Nuevas evidencias formativas en la Puna de Atacama (norte de Chile). In: Formativo Sudamericano. Una Revaluación. Simposio Internacional de Arqueología Sudamericana (Lederberger-Crespo, P., ed.): 227-242; Ecuador: Cuenca.

NÚÑEZ, L., 2005 - La orientación minero-metalúrgica en la sociedad atacameña. In: Esferas de interacción prehistóricas y fronteras nacionales modernas en los Andes Sur Centrales $(\mathrm{H}$. Lechtman, ed.). Lima: IEP (en prensa).

NÚÑEZ, L. \& DILLEHAY, T., 1979 - Movilidad giratoria, armonía social y desarrollo en los Andes meridionales: patrones de tráfico e interacción económica, 190 p.; Universidad Católica del Norte.

NÚNẼEZ, L., GROSJEAN, M. \& CARTAJENA, I., 1999a - Un ecorefugio oportunístico en la Puna de Atacama durante eventos áridos del Holoceno Medio. Estudios Atacameños, 17: 125174. 
NÚÑEZ, L., GROSJEAN, M. \& CARTAJENA, I., 1999b - Evaluación paleoambiental de las ocupaciones paleoindio y arcaico temprano en la puna de Atacama (Norte de Chile). National Geographic Society, ${ }^{\circ}$ 583696. Informe final. Ms.

NÚÑEZ, L., CARTAJENA, I., CARRASCO, C. \& DE SOUZA, P., 2003 - Informe Anual Proyecto FONDECYT 1020316. Ms.

NúÑEZ, L., CARTAJENA, I., CARRASCO, C. \& DE SOUZA, P., 2004 - Informe Anual Proyecto FONDECYT 1020316. Ms.

NúÑEZ, L., CARTAJENA, I., CARRASCO, C. \& DE SOUZA, P., 2005a - Informe Anual Proyecto FONDECYT 1020316. Ms.

NúÑEZ, L., CARTAJENA, I., CARRASCO, C. \& DE SOUZA, P., 2005b (en prensa) - Patrones, cronología y distribución del arte rupestre arcaico tardío y formativo temprano en la cuenca de Atacama. In: Tramas en la piedra (Fiore, D. \& Podesta, M., eds.)

NÚÑEZ R., V. A., 1998 - Arqueología, historia y antropología de los sitios de Alamito, 346 p.; Editorial Interdea.

ONUKI, Y., 1994 - Las actividades ceremoniales tempranas en la cuenca del Alto Huallaga y algunos problemas generales. In: El mundo ceremonial andino (L. Millones \& Y. Onuki, eds.): 71-95); Lima: Horizonte.

PEREIRA, D., SANZETENEA, R. \& BROCKINGTON, D. L., 2001 - Investigaciones del proyecto arqueológico formativo en Cochabamba, Bolivia. Textos Antropológicos, 13 (1-2): 167182 (Rivera, C., Michel, M. R. \& Capriles, J. M., eds.).

PONCE, C., 1964 - El templete semisubterráneo de Tiwanaku, 90 p.; La Paz: Biblioteca de Arte y Cultura.

PONCE, C., 1970 - Wankarani, Chiripa y la relación con Tiwanaku, 79 p.; La Paz: Academia Nacional de Ciencias de Bolivia, 25.

REDMAN, CH. L., 1978 - The rise of civilization, 367 p.; San Francisco: W. H. Freeman and Company.

REDMAN, CH. L., 1991 - Los orígenes de las civilizaciones. Desde los primeros agricultores hasta la sociedad urbana en el próximo oriente (Picazo, M., trad.); Barcelona; Editorial Crítica.

REES, C., 1999 - Elaboración, distribución y consumo de cuentas de malaquitas durante el periodo Formativo en la vega de Turi y sus inmediaciones, subregión del río Salado, norte de Chile. In: Los tres reinos: Práctica de recolección (Aschero, C. A., Korstanje, M. A. \& Vuoto, P. M., eds.): 83-94; Instituto de Arqueología y Museo, Universidad Nacional de Tilcara.

REES, C. \& DE SOUZA, P. (en prensa) - Producción lítica durante el periodo Formativo en la subregión del río Salado. Chungará, número especial; Arica. Actas XV Congreso Nacional de Arqueología Chilena.

RENFREW, C., 1974 - Beyond a subsistence economy: The evolution of social organisation in prehistoric Europe. In: Reconstructing Complex Society: An Archaeological colloquium (C. B. Moore, ed.): 69-95.

ROSE, C., 2001 - Organización residencial en una aldea del Periodo Formativo Temprano: El sitio Wankarani de la Barca, Oruro. Textos Antropológicos, 13 (1-2): 147-165 (Rivera, C., Michel, M. R. \& Capriles, J. M., eds.).

RÖSING, I., 1991 - Las almas nuevas del mundo Callawaya. Análisis de la curación ritual Callawaya para vencer penas y tristezas, vol. II. Estudios Callawayas, I; La Paz - Cochabamba.

RÖSING, I., 1994 - La deuda de ofrenda: Un concepto central de la religión andina. Revista Andina, 12 (1): 191-216.

SERVICE, E., 1962 - Primitive social organisation: an evolutionary perspective, 211 p.; New York: Random House.

SOLC, V., 1969 - Los aymaras de las islas del Titicaca, 194 p.; México. Instituto Indigenista Interamericano Antropología Social, 12. 
TARRAGÓ, M., 1989 - Contribución al conocimiento de las poblaciones de los oasis de San Pedro de Atacama en relación con los otros pueblos púnenos, en especial el sector del valle Calchaquí. Tesis de Doctorado, Universidad Nacional de Rosario, Argentina.

TARRAGÓ, M., 1976 - Alfarería típica de San Pedro de Atacama (Norte de Chile). Estudios Atacameños, 4: 37-64.

URIBE, M., 2004 - La cerámica arqueológica del sitio Tulán 54: Análisis tipológico y depositacional de un sitio formativo temprano del Salar de Atacama. Informe de avance Proyecto FONDECYT 1020316. Ms.

VENTURA, B., 1999 - Arqueología de los valles orientales y las serranías de Zenta y Santa Victoria, Salta. Tesis Doctoral, Universidad de Buenos Aires. Ms.

VICENT, J. M., 1999 - Problemas teóricos de la arqueología de la muerte. Una introducción. In: Arqueología da Morte la península ibérica desde as orixes asta o medievo (Fabregas, R., ed.): 13-31. Serie Cursos e Congresos 3, Xinzo de Limia.

WALTER, H. \& TRIMBORN, H., 1994 [1966] - Excavación mound Huancarani. In: Investigaciones de arqueólogos alemanes en Bolivia (Distel, A. I., trad.), 136 p.; Buenos Aires: Colección Mankacen CAEA. 